\title{
Composition of intestinal Enterobacteriaceae populations of healthy domestic pigs
}

\author{
Peter Schierack, ${ }^{1}$ Nicole Walk, ${ }^{1}$ Katja Reiter, ${ }^{2}$ Karl D. Weyrauch ${ }^{2}$ \\ and Lothar H. Wieler ${ }^{1}$ \\ ${ }^{1}$ Institut für Mikrobiologie und Tierseuchen, Freie Universität Berlin, Philippstr. 13, 10115 Berlin, \\ Germany \\ ${ }^{2}$ Institut für Veterinär-Anatomie, Freie Universität Berlin, Koserstr. 20, 14195 Berlin, Germany
}

Correspondence

Peter Schierack

schierack.peter@vetmed.

fu-berlin.de

Received 31 May 2007

Revised 19 July 2007

Accepted 23 July 2007

\section{INTRODUCTION}

The family Enterobacteriaceae consists of many genera and strains that colonize the small and large intestine, and includes members of the non-pathogenic autochthonous (commensal) microbiota as well as pathogens. Several pathogenic Enterobacteriaceae, especially Escherichia coli strains, cause diarrhoea, urinary tract infections, mastitis, arthritis and meningitis in both humans and animals (Alexander, 1994; Ewers et al., 2007; Fairbrother et al., 2005; Hermansson et al., 1978; Kaper et al., 2004; Nagy \& Fekete, 2005).

A number of studies of pathogenic $E$. coli have been performed, partly because E. coli is economically one of the most important pathogenic bacteria in pig production (Barth et al., 2007; Fairbrother et al., 2005; Nagy \& Fekete, 2005; Wieler et al., 2001). However, few data are available on the composition of the commensal E. coli microbiota in

Figures showing electron micrographs of mucosa-attached bacteria, the incidence of haemolysis among E. coli colonies, and the ECOR grouping of $E$. coli from pigs, are available as supplementary data with the online version of this paper. pigs. The E. coli microbiota in pigs appears to be individual, dynamic and age-dependent (Katouli et al., 1995, 1999), and determinations of the Enterobacteriaceae microbiota are generally only snapshots of a highly dynamic intestinal steady state. It has also been reported that the E. coli microbiota in pigs is highly structured, and that different compartments of the gut are preferentially colonized by distinct phylogenetic E. coli clones (Dixit et al., 2004).

Compared to E. coli, there are very little data about other non-pathogenic or facultatively pathogenic Enterobacteriaceae species. The few studies deal almost exclusively with those associated with sporadic infections, virulence determinants, antibiotic resistance or metabolism. To our knowledge, data about their distribution in the intestine, ratios to other Enterobacteriaceae species and diversity under physiological conditions have not been reported.

The aim of this study was to evaluate the Enterobacteriaceae populations in healthy domestic pigs, with consideration of their intestinal distribution, relative ratios and diversity. $E$. coli isolates were further evaluated for the presence of virulence genes, haemolysis and phylogenetic affiliation. In 
addition, the effects of probiotic Enterococcus faecium feed supplementation on the Enterobacteriaceae microbiota were examined.

\section{METHODS}

Animal housing. Piglets (hybrids of Deutsche Landrasse and Duroc) were stalled in groups and fed according to the National Research Council (NRC) recommendations (National Research Council, 1998). Piglets had ad libitum access to feed, with (probiotic piglets) or without (control piglets) probiotic supplementation. The principal components of the liquid diet were wheat and soybean. The administration of antibiotics was prohibited for both sows and piglets for at least 3 months prior to the trial. In addition, the health status of piglets was monitored for signs of clinical illness. The study was approved by the local animal welfare committee of the Federal Ministry of Agriculture, Food and Consumer Protection, Germany (no. G0037/02).

The probiotic strain Ent. faecium SF68 (NCIMB 10415; Benyacoub et al., 2003; Wunderlich et al., 1989) was obtained from a commercial batch of the feed additive Cylactin (Cerbios-Pharma). The mean concentration of the Ent. faecium in the feed was $2.0 \pm 0.4 \times 10^{5}$ viable cells per gram food, as determined by colony hybridization (Macha $e t$ al., 2004). Supplementation resulted in approximately $10^{3}$ c.f.u. (g wet weight $)^{-1}$ of Ent. faecium SF68 in faeces of probiotic piglets. The absence of the probiotic strain in control piglets was confirmed in random faecal samples.

Cultivation of Enterobacteriaceae. Enterobacteriaceae were isolated from either the distal jejunum $(50 \mathrm{~cm}$ proximal to the Plica ileocaecalis) or the proximal colon (apex of the ascending colon) of piglets from different litters. The distal jejunum was chosen as representative of the small intestine, since the more proximal jejunum generally contained no intestinal contents, and bacteria of different sections of the small intestine are thought to be similar (Dixit et al., 2004). The proximal colon was chosen as part of the large intestine, as other authors have found a uniformity of bacterial adhesion at a number of sites of the large intestine, indicating that small biopsy samples are likely to be representative of wide areas of the gut epithelium (Hartley et al., 1979; Swidsinski et al., 2002). Piglets aged 56 days post-partum were euthanized by injection with sodium Pentobarbital, and clamped intestinal sections were removed for bacterial isolation from intestinal contents. Enterobacteriaceae were isolated from intestinal contents and mucosa and plated by serial dilutions on Gassner agar plates. Bacteria from the mucosa included bacteria associated to mucus and epithelial cells.

Mucus and epithelial cells were derived from an $\sim 2 \times 5 \mathrm{~cm}$ section of intestinal tissue, as described elsewhere (Solano-Aguilar et al., 2000). Briefly, sections of intestinal tissues were washed twice in PBS to remove visible faecal material. Tissues were transferred to an Erlenmeyer flask containing $25 \mathrm{ml}$ PBS and incubated for $5 \mathrm{~min}$ (220 r.p.m., $37^{\circ} \mathrm{C}$ ). It was expected that these short washing steps would not affect mucosa-attached bacteria, as other authors have reported high numbers of mucosa-attached or epithelial cell-attached E. coli even after four to six changes of physiological saline washes (Hartley et al., 1979; Swidsinski et al., 2002). The resulting suspension was removed and plated to Gassner agar plates. For mucus extraction, tissues were incubated in $25 \mathrm{ml}$ Hanks' balanced salt solution/DTT [HBSS-DTT; HBSS without $\mathrm{Ca}^{2+}$ and $\mathrm{Mg}^{2+}$ (Cambrex), $2 \mathrm{mM}$ DTT, $0.01 \mathrm{mM}$ HEPES] for $10 \mathrm{~min}\left(220\right.$ r.p.m., $\left.37{ }^{\circ} \mathrm{C}\right)$. The suspension was passed through sterile $210 \mu \mathrm{m}$ nylon mesh (Sefar) and plated to Gassner agar plates. For epithelial cell isolation, washed tissues were incubated with $25 \mathrm{ml}$ HBSS-EDTA (HBSS without $\mathrm{Ca}^{2+}$ and $\mathrm{Mg}^{2+}$, $1 \mathrm{mM}$ EDTA, $1 \mathrm{mM}$ HEPES) for $45 \mathrm{~min}$ (220 r.p.m., $\left.37^{\circ} \mathrm{C}\right)$. The suspension was passed through sterile $210 \mu \mathrm{m}$ nylon mesh and plated to Gassner agar plates. Three additional controls were performed to determine the reliability of the procedure with respect to isolation of Enterobacteriaceae associated with epithelial cells: (1) solutions were sporadically tested for the presence of epithelial cells by light microscopy; (2) tissue sections were directly laid on Gassner agar plates after the last wash step to transfer attached bacteria; and (3) approximately $1 \mathrm{~g}$ mucosal tissue was homogenized in PBS after the second wash with a Dounce homogenizer, and homogenates were plated to Gassner agar plates.

Enterobacteriaceae-like colonies on Gassner agar plates were randomly picked and replica-plated to CHROMagar Orientation plates (Merlino et al., 1996). The differences in the numbers of tested isolates between pigs and intestinal sections were due to the substantial variation in the absolute numbers of mucosa-attached bacteria from each pig. Blue/green/yellow Enterobacteriaceae-like colonies on Gassner agar plates that appeared violet on CHROMagar Orientation plates were initially defined as E. coli. The haemolytic activity of these colonies $(n=3471)$ was tested on sheep blood agar plates. After macrorestriction analysis of 643 E. coli isolates, each clone determined was finally verified as E. coli using LIM agar, Kligler agar, urea agar, citrate agar and malonate liquid culture. Blue/green/yellow Enterobacteriaceae-like colonies on Gassner agar plates which were blue or white on CHROMagar Orientation plates were initially defined as bacteria other than E. coli. After macrorestriction analysis, non-E. coli clones were finally tested using API 20E (bioMérieux) tests for further species identification. Four E. coli isolates initially isolated from the jejunum of piglet A were not recovered after storage and were therefore not included in the data shown.

Scanning electron microscopy and periodic acid-Schiff (PAS) staining. Intestinal segments were cut open lengthwise at the antimesenterial side, washed twice in PBS to remove visible faecal material, and fixed in $0.1 \mathrm{M}$ cacodylate buffer, $2 \%$ paraformaldehyde, $2.5 \%$ glutaraldehyde ( $\mathrm{pH} 7.2$ ). Samples were postfixed in $1 \%$ osmium tetroxide. After dehydration in a graded series of ethanol and hexamethyldisilazane (HMDS; Roth), they were mounted on aluminium stubs, sputter-coated with gold and finally examined using a scanning electron microscope (Nanolab 2000, Bausch \& Lomb). For the PAS reaction after washing, segments were fixed in $4 \%$ paraformaldehyde and embedded in paraffin. Mucopolysaccharides were demonstrated using PAS reagents (Merck).

Virulence gene and ECOR (E. coli Reference Collection) group determinations using PCR. The presence of virulence genes associated with porcine pathogenic E. coli, faeG, fanA, fasA, fedA, fimF41a (F4, F5, F6, F18, F41 fimbriae), stx2e (shigatoxin 2e), est-Ia, est-II (heat-stable toxins 1 and 2) and eltB-Ip (heat-labile toxin), was determined by PCR for all E. coli clones isolated, as previously described (Moon et al., 1999; Schierack et al., 2006). The E. coli phylogenetic groups of all detected clones were determined by PCR, as described by Clermont et al. (2000).

Discrimination of Enterobacteriaceae strains by macrorestriction analysis and calculation of diversity. Enterobacteriaceae colonies were differentiated by macrorestriction analysis (PFGE), as previously described (Moser et al., 2002). Bacterial DNA was digested with $\mathrm{XbaI}$ (Promega). If the macrorestriction patterns of isolates did not differ by more than one band, these isolates were considered to belong to a single clone. The diversity of the coliform bacteria was determined using Simpson's index of diversity $\left(D_{\mathrm{i}}\right)$ as described elsewhere (Hunter \& Gaston, 1988; Katouli et al., 1999). This calculation allows comparisons of the diversity of populations to be made, even where different numbers of isolates are included. 


\section{RESULTS}

\section{Comparison of Enterobacteriaceae populations between probiotic and control piglets}

The 15 piglets included in this study showed no clinical symptoms of disease. There were also no obvious differences between animals of the probiotic and the control groups with respect to the numbers, composition, mucosal attachment, intestinal distribution or diversity of intestinal Enterobacteriaceae, or the occurrence of virulence gene-positive and haemolytic E. coli (Table 1, Figs 1 and 2, Supplementary Figs S2 and S3). Further analyses of the Enterobacteriaceae from both groups were therefore based on pooled samples, which were treated as a representative population.

\section{Sporadic absence of Enterobacteriaceae in the distal jejunum; comparative characterization of colonies from the mucosa with those from intestinal contents}

In four cases, we were unable to isolate any Enterobacteriaceae from the distal jejunum of the animals. Although high numbers of Enterobacteriaceae from intestinal contents of other animals were detected, generally only low numbers of bacteria associated with the mucus and the epithelial-cell fractions from these same animals were isolated (Table 1). We therefore tested the applicability of the established protocol. Treatment of the mucosa with EDTA-containing solutions resulted in the release of single epithelial cells, and this was confirmed using light microscopy. The numbers of bacterial colonies per mucosal sample (mucus plus epithelial cells) were similar using the physiological buffer and EDTA solutions compared to tissue homogenization with a homogenizer. If no bacteria were detectable with the physiological buffer and EDTA solutions and tissue homogenization with a homogenizer, no bacteria were detected after direct contact-transfer of tissues to Gassner agar plates. Using electron microscopy, it was shown that even the first washing step removed a considerable proportion of the secreted mucins, although remnants remained visible (see Supplementary Fig. S1A, B). Cell-bound mucins were not removed, as confirmed in parallel studies using PAS staining.

High numbers of bacteria associated with the mucosa were only found sporadically, including bacteria associated with the remaining secreted mucins, cell-bound mucins and glycocalyx. As shown in Table 1, the numbers of associated Enterobacteriaceae varied considerably, with large differences from animal to animal that appeared to be speciesdependent. Even when strong attachment was observed, $<10^{-4}$ attached bacteria per epithelial cell was determined. From 11 animals, $<100$ colonies were isolated from the mucosa of the jejunum, corresponding to $<10^{-9}$ bacteria per epithelial cell. The low numbers of mucosa-associated Enterobacteriaceae were verified by scanning electron microscopy, which also showed only sporadically associated bacteria (see Supplementary Fig. S1C, D). Comparing the sparse colonies from the mucus with those from the epithelial-cell fractions, the diversity was similar, and often the same bacterial clones were detected in both fractions.

An obvious difference in the occurrence of clones between the intestinal contents and the mucosa was found in one jejunal sample. In all other samples, most clones were

Table 1. Association of Enterobacteriaceae with the mucosa

Association was calculated by enumeration of the colonies isolated from the mucosa (pool of cells associated with mucus and epithelial cells). Animals A-H were control piglets, and animals I-O were probiotic piglets.

\begin{tabular}{|c|c|c|c|c|c|c|c|c|}
\hline \multirow[t]{2}{*}{ Sample } & \multicolumn{8}{|c|}{ Piglet (control) } \\
\hline & A & B & $\mathrm{C}$ & D & $\mathrm{E}$ & F & G & $\mathbf{H}$ \\
\hline $\begin{array}{l}\text { Mucosa, } \\
\text { jejunum }\end{array}$ & $1.7 \times 10^{3 *} \dagger$ & $1.1 \times 10^{3}$ & $1 \times 10^{4} \ddagger$ & 0 & 0 & 11 & 0 & 0 \\
\hline \multirow[t]{3}{*}{ Mucosa, colon } & $6.7 \times 10^{5}$ & $5 \times 10^{2} \S$ & $3 \times 10^{3} \|$ & 0 & $2.7 \times 10^{4}$ & $9.2 \times 10^{3}$ & 17 & $6.4 \times 10^{2}$ \\
\hline & \multicolumn{8}{|c|}{ Piglet (probiotic) } \\
\hline & I & $\mathbf{J}$ & $\mathbf{K}$ & $\mathbf{L}$ & $\mathbf{M}$ & $\mathbf{N}$ & O & \\
\hline $\begin{array}{l}\text { Mucosa, } \\
\text { jejunum }\end{array}$ & 0 & $3.8 \times 10^{3}$ & 4 & 26 & 0 & 36 & 5 & \\
\hline Mucosa, colon & $3.1 \times 10^{6}$ & $1.2 \times 10^{3}$ & $1 \times 10^{3}$ & $2.4 \times 10^{3} \boldsymbol{g}$ & 0 & $5.6 \times 10^{2}$ & $1.8 \times 10^{3}$ & \\
\hline
\end{tabular}

${ }^{*}$ Total numbers of mucosa-associated bacteria.

$\nmid 92 \%$ C. freundii, $3 \%$ E. coli, $5 \%$ others, not defined.

$\$ 95 \%$ Ent. cloacae, $5 \%$ E. coli.

$\$ 80 \%$ E. coli, $20 \%$ others, not defined.

$1192 \%$ E. coli, $8 \%$ Ent. cloacae.

S84\% K. pneumoniae, $16 \%$ E. coli. 


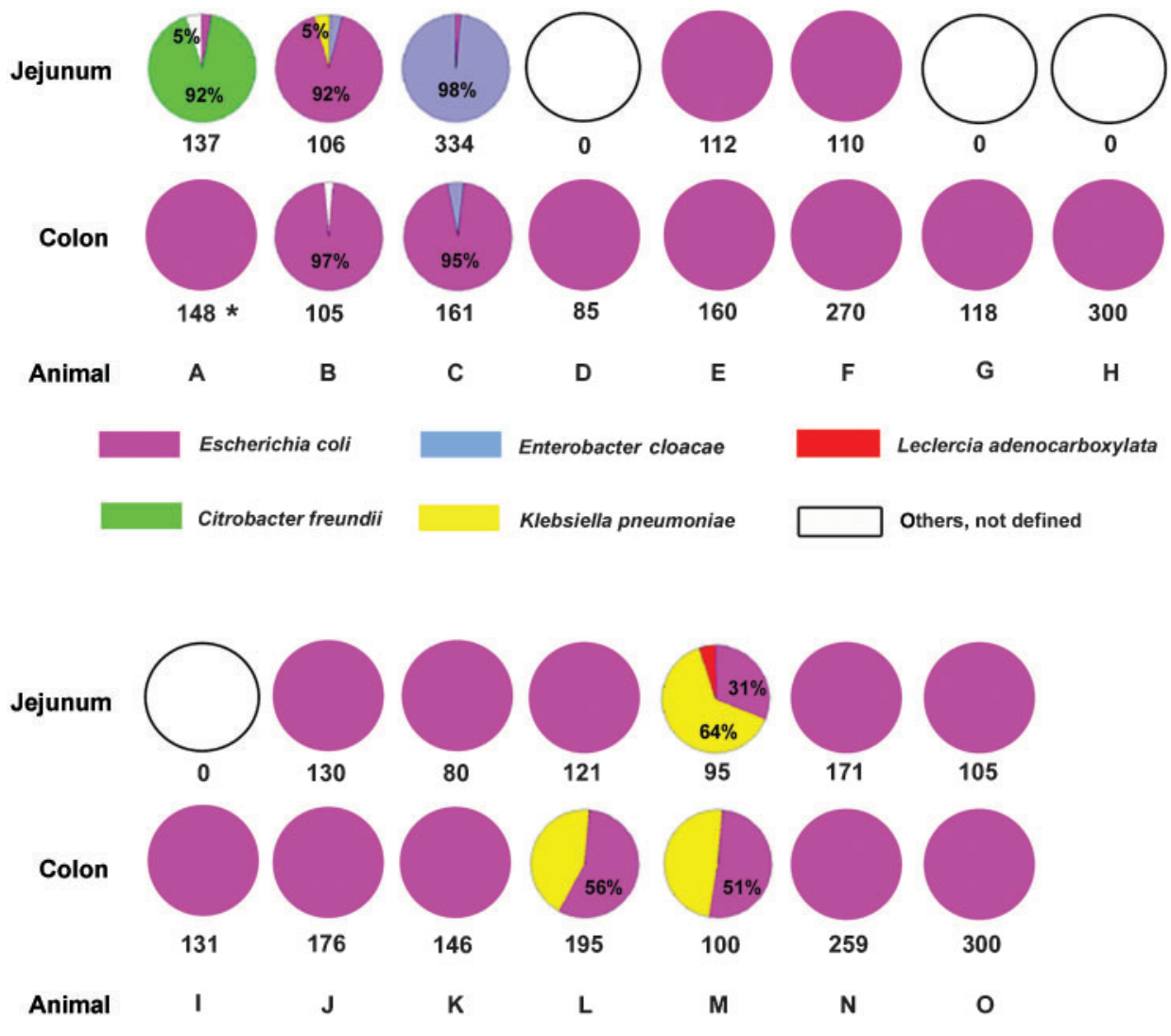

Fig. 1. Enterobacteriaceae species. Bacterial species were determined from data derived from bacterial behaviour on plates and from macrorestriction analysis. All isolates tested in this study are shown, including bacteria from the mucosa as well as from intestinal contents. Animals A-H were control piglets, while animals I-O were probiotic piglets. From animals A and I, only data from the mucosa were available. *Number of tested colonies.

found to be associated with both the mucosa and intestinal contents, and the dominant clones of the intestinal contents were the dominant clones of the mucosa. Likewise, the diversity of $E$. coli from both fractions was similar. For these reasons, and due to the low numbers of mucosa-associated bacteria, data for one intestinal section (mucosa and intestinal contents) were pooled for further comparison between the jejunal and the colonic sections.

\section{Identification and numbers of isolated Enterobacteriaceae}

In four animals, Enterobacteriaceae-like isolates were not detected in the jejunum. Whenever Enterobacteriaceae were cultivated from the jejunum of the other animals, E. coli was always present. In four animals, Enterobacter cloacae and/or Klebsiella pneumoniae and/or Leclercia adecarboxylata or Citrobacter freundii were also detected. Isolates of these species in some cases dominated the Enterobacteriaceae microbiota. In the colon, Enterobacteriaceae-like bacteria, including E. coli, were always present. In three animals, Ent. cloacae or K. pneumoniae were also detected, although these species did not dominate (Fig. 1).

\section{Diversity of Enterobacteriaceae other than E. coli and diversity of $E$. coli strains}

In contrast to E. coli, only one clone of each non-E. coli species was detected in a single animal (with the exception of one animal). In that animal, one specific Ent. cloacae clone was detected in the jejunum and a second Ent. cloacae clone in the colon. When E. coli was present in one intestinal section, in general more than one clone could be recovered. The diversity of $E$. coli was on average higher in the colon $\left(D_{\mathrm{i}}=0.61 \pm 0.23\right)$ than in the jejunum $\left(D_{\mathrm{i}}=0.39 \pm 0.26\right)$. The $E$. coli diversity was only sporadically higher in the jejunum than in the colon. E. coli clones from the jejunum were also found in the colon of the same animal. The occurrence of Enterobacteriaceae other than E. coli did not affect the diversity of E. coli (Fig. 2).

\section{Virulence genes in E. coli clones}

Virulence gene-positive E. coli were isolated from eight animals. These E. coli were always found in the colon, and in three of the eight animals also in the jejunum. Up to four different clones originating from one animal were virulence gene-positive, with virulence gene profiles stx2e, 


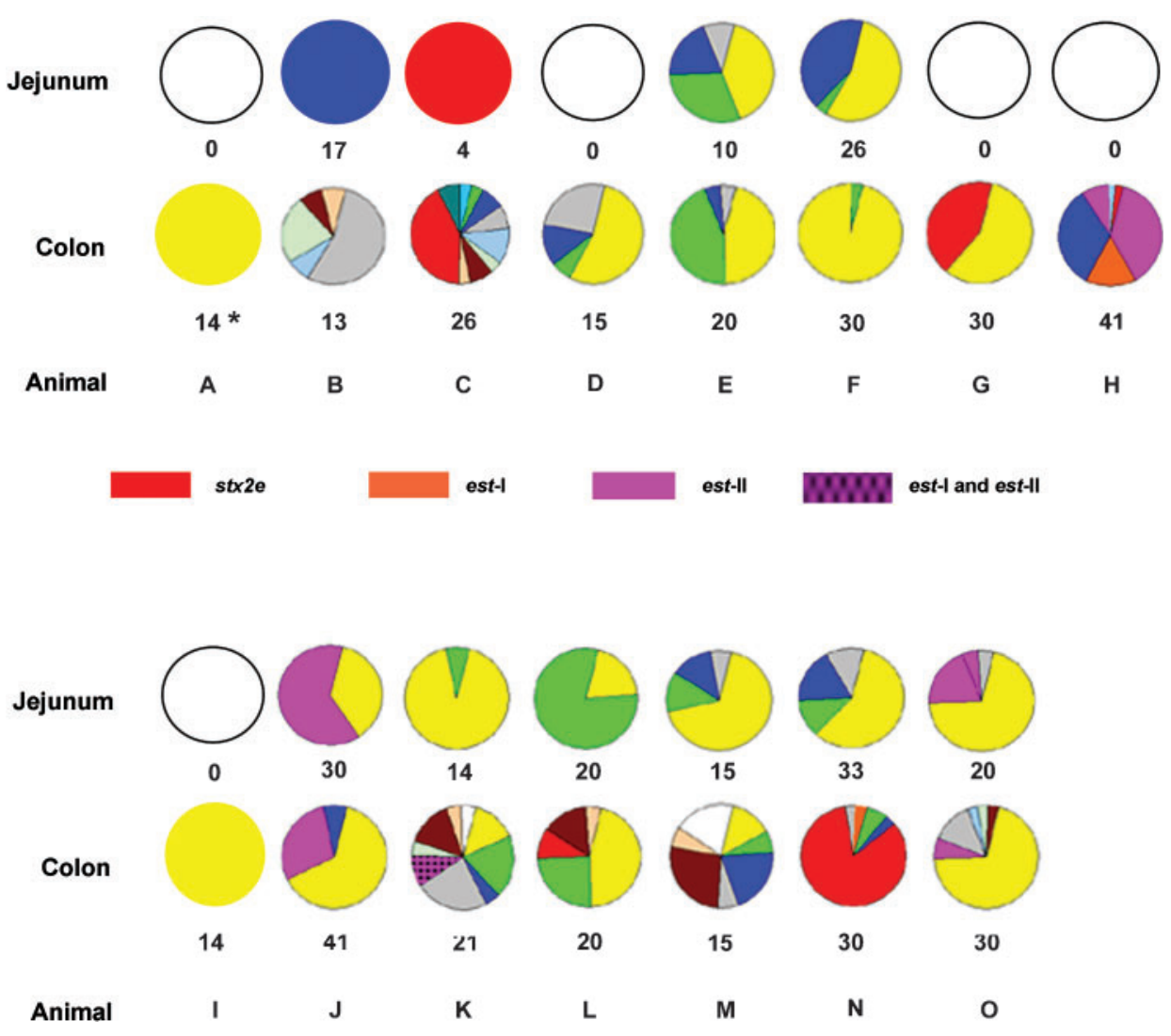

Fig. 2. Diversity of $E$. coli colonies. The diversity of $E$. coli was determined using macrorestriction analysis. Coloured sections indicate only $E$. coli clones isolated from intestinal sections within a given animal; the colours do not necessarily share identity with clones represented by the same colour in other animals. The distribution of virulence gene-positive $E$. coli is also shown within the same graphics, indicated by the colours shown. In animals $\mathrm{H}$ and $\mathrm{O}$, two different clones were est-II-positive. Animals A-H were controls; animals $\mathrm{I}-\mathrm{O}$ were probiotic piglets. From animals $\mathrm{A}$ and I, only data from the mucosa were available. *Number of tested colonies.

est-Ia, est-II or est-Ia + est-II. In some cases, virulence genepositive E. coli were also found to dominate the E. coli population (Fig. 2).

\section{Haemolytic E. coli}

Haemolytic E. coli were detected in seven animals. Such strains were occasionally also found to dominate the E. coli microbiota (see Supplementary Fig. S2). However, the occurrence of haemolytic E. coli did not affect the diversity of the E. coli population. None of the haemolytic E. coli possessed any of the tested virulence genes.

\section{ECOR groups of $E$. coli clones}

Isolates of each of the four ECOR groups were found in the jejunum as well as in the colon. ECOR group A isolates were mostly detected, regardless of which intestinal section was investigated, followed by ECOR groups B2, D and B1. Isolates from ECOR groups $\mathrm{A}, \mathrm{B} 2$ and $\mathrm{D}$ were able to dominate the E. coli microbiota (see Supplementary Fig. S3).

\section{DISCUSSION}

This study indicates that the intestinal Enterobacteriaceae population of pigs is highly individual. If Enterobacteriaceae were isolated, E. coli was always isolated and dominated most samples. The most common member of the Enterobacteriaceae of the porcine intestine was E. coli, consistent with a previous study of 642 Australian mammals in which E. coli was the most common of the 24 enteric species recovered (Gordon \& FitzGibbon, 1999). However, in several samples, E. coli numbers were lower than numbers of Ent. cloacae, K. pneumoniae and $C$. freundii. The dominant species or single dominating E. coli clone of an intestinal section was not necessarily found in the other intestinal section. Many different clones of E. coli were found to colonize the intestinal tract of pigs, whereas other Enterobacteriaceae species were always found to be represented by a single clone in an intestinal section. Two possible explanations could be advanced for the latter observation: either only one clone of a species other than $E$. coli colonizes an intestinal section, or only one clone always dominates, such that other clones are not detectable. 
However, both possibilities are conceivable, since Enterobacteriaceae species other than E. coli can also be highly diverse in animal populations. In a previous study, the genome diversity of intestinal Enterobacteriaceae from a variety of Australian mammals was estimated, and a high diversity among species was reported, with $C$. freundii exhibiting the highest diversity (Gordon \& Lee, 1999).

E. coli, Ent. cloacae, K. pneumoniae and C. freundii can all be isolated as dominant Enterobacteriaceae in pigs. Information about the distribution in hosts of Enterobacteriaceae other than E. coli generally relates to pathogenicity. Ent. cloacae, K. pneumoniae, C. freundii and L. adecarboxylata are thought to be opportunistic pathogens. Most data about these species relate to human infection (de Baere et al., 2001; Fattal \& Deville, 2000; Kumar \& Sharma, 1978; Omwandho et al., 2006; Scheld \& Tyson, 1979; Temesgen et al., 1997; Tschape et al., 1995). Data from pigs are not available, are very scarce or have not been related to infection or distribution in the intestine (Bertschinger et al., 1977; Ross et al., 1975). In this study it was shown that the porcine intestine is a source of all these different Enterobacteriaceae species. However, while they successfully colonize the intestine, they do not appear to affect the health of their hosts, despite high numbers.

The occasionally poor yield of mucosa-associated Enterobacteriaceae contrasts with previous reports, in which $10^{3}-10^{9}$ E. coli per gram mucosal tissue was found even after four to six physiological saline washes (Hartley et al., 1979; Swidsinski et al., 2002). In only four mucosal samples were more than $10^{3}$ Enterobacteriaceae per gram isolated, despite the high recovery of Enterobacteriaceae in intestinal contents. Although the secreted mucin layer could have been removed by the two short washes, bacteria attached to the remaining secreted mucin layer or to the surface of the epithelial cells were never detected in high numbers. We conclude that Enterobacteriaceae do not necessarily have to adhere to the mucosa in high numbers to successfully colonize the intestine.

Haemolysis by E. coli is thought to correlate with the presence of virulence genes and therefore with pathogenicity (Frydendahl, 2002). In a previous study, the majority of haemolytic $E$. coli clones isolated in a swine population were found to harbour no virulence genes and were therefore considered to be non-pathogenic (Schierack et al., 2006). In this study, seven animals harboured haemolytic E. coli in the jejunum and/or the colon. Confirming our previous results, these haemolytic clones did not harbour virulence genes. Furthermore, even when present in high numbers in a given intestinal section (up to $78 \%$ of all E. coli isolates), these E. coli did not affect the health status of the piglets, which showed no signs of disease. Haemolysis alone would therefore appear not to be an indicator of virulence, and does not correlate with the presence of other virulence-related markers.

It is generally accepted that bacterial intestinal pathogens have to compete successfully with the autochthonous microbiota of the host, adhere to the intestinal wall and proliferate to cause disease. Most porcine pathogenic E. coli adhere to specific membrane receptors on villous enterocytes of the small intestine, and autochthonous bacteria have been shown to block adhesion of pathogenic bacteria to these receptors (Cox \& Houvenaghel, 1993; Fujiwara et al., 1997; Schroeder et al., 2006). Likewise, other bacteria introduced into the intestinal microbiota can also affect the course of infection by intestinal pathogens. For example, it has been shown both in vivo and in vitro that probiotic bacteria can prevent infection and disease caused by Salmonella and pathogenic E. coli (Kleta et al., 2006; Schroeder et al., 2006). The presence of probiotics or the integrity of a 'protective' intestinal mucosa-related microbiota have therefore been considered to be possibilities for the prevention of infection (Kuhbacher et al., 2006). However, in this study, no or only very low numbers of Enterobacteriaceae in jejunal sections were detected. Even homogenized intestinal mucosa plated onto blood agar or CHROMagar plates was essentially bacteria-free, suggesting that this phenomenon might also apply to other bacterial species (e.g. lactobacilli or enterococci, which would be detectable on the CHROMagar plates). These observations suggest that the efficacy of the protective effects of specific established species in healthy individuals should be considered critically, as there are clear indications that no bacteria of otherwise abundant species are associated with intestinal sections.

Probiotic Ent. faecium supplementation showed no significant effect on the numbers and diversity of Enterobacteriaceae species, or on the total counts, diversity, haemolysis and distribution of virulence gene-positive $E$. coli. However, additional probiotic effects have recently been attributed to this strain (Lodemann et al., 2006; Pollmann et al., 2005; Taras et al., 2006), and Ent. faecium has been reported to reduce the incidence of potentially pathogenic E. coli, as defined by serotypes associated with disease (Scharek et al., 2005). Based on the results of this study, however, these probiotic effects are unlikely to be the result of general effects on the commensal Enterobacteriaceae microbiota. Ent. faecium might affect other intestinal bacterial species, as has been shown for other probiotics, e.g. lactobacilli, which increase the richness and diversity of intestinal bacteria (Kuhbacher et al., 2006; Lan et al., 2004).

E. coli populations in swine have been reported to be highly structured in their intestinal distribution (Dixit et al., 2004). In this study, we found no association between the occurrence of $E$. coli clones in intestinal sections and a specific phylogenetic ECOR group. However, a few clones dominant in the jejunum were not detected in the colon when the diversity increased. Nonetheless, these clones might still successfully colonize the jejunum as well as the colon. We suggest that E. coli populations might not be as structured as previously proposed. Such associations between phylogenetically distinct animal/bacterial species and a specific biotope are based on the existence of spatially 
determined habitats over long periods. This might not be an appropriate model for $E$. coli, since developments in animal production and breeding, changing feeding regimes and controlled housing conditions might have altered the intestinal milieu of swine and promoted colonization by more adaptive clones rather than distinct phylogenetic groups. In addition, E. coli can exchange genetic information, which also supports the establishment of $E$. coli in broadly varying habitats. We therefore consider it unlikely that specific clones are adapted to specific intestinal sections.

In conclusion, the Enterobacteriaceae microbiota of pigs is particular to the individual, and several different species can dominate. Attachment of bacteria to the mucosa in high numbers does not appear to be essential for successful colonization. While E. coli is the dominant species, it shows a high diversity. Finally, haemolytic E. coli and E. coli with many different virulence factor gene profiles can also establish in high numbers without affecting the health of their hosts, suggesting a low association between haemolysis or the presence of virulence genes and virulence or pathogenicity.

\section{ACKNOWLEDGEMENTS}

This work was supported by grant FOR 438/1-1 from the Deutsche Forschungsgemeinschaft. We thank A. Luebke-Becker for identification of Enterobacteriaceae and $\mathrm{K}$. Tedin (both Institut für Mikrobiologie und Tierseuchen, Berlin) for carefully reading the manuscript.

\section{REFERENCES}

Alexander, T. J. L. (1994). Neonatal Diarrhoea in Pigs. Wallingford, UK: CAB International.

Barth, S., Tscholshiew, A., Menge, C., Weiß, R., Baljer, G. \& Rolf Bauerfeind, R. (2007). Virulence and fitness gene patterns of Shiga toxin-encoding Escherichia coli isolated from pigs with edema disease or diarrhea in Germany. Berl Munch Tierarztl Wochenschr 120, 307316.

Benyacoub, J., Czarnecki-Maulden, G. L., Cavadini, C., Sauthier, T., Anderson, R. E., Schiffrin, E. J. \& von der Weid, T. (2003). Supplementation of food with Enterococcus faecium (SF68) stimulates immune functions in young dogs. J Nutr 133, 1158-1162.

Bertschinger, H. U., Pohlenz, J. \& Middleton-Williams, D. M. (1977). Studies on the mastitis-metritis-agalactia syndrome (milk fever) in sows. III. Galactogenic induction of Klebsiella-induced mastitis. Schweiz Arch Tierheilkd 119, 265-275. (in German)

Clermont, O., Bonacorsi, S. \& Bingen, E. (2000). Rapid and simple determination of the Escherichia coli phylogenetic group. Appl Environ Microbiol 66, 4555-4558.

Cox, E. \& Houvenaghel, A. (1993). Comparison of the in vitro adhesion of K88, K99, F41 and P987 positive Escherichia coli to intestinal villi of 4- to 5-week-old pigs. Vet Microbiol 34, 7-18.

de Baere, T., Wauters, G., Huylenbroeck, A., Claeys, G., Peleman, R., Verschraegen, G., Allemeersch, D. \& Vaneechoutte, M. (2001). Isolations of Leclercia adecarboxylata from a patient with a chronically inflamed gallbladder and from a patient with sepsis without focus. $J$ Clin Microbiol 39, 1674-1675.
Dixit, S. M., Gordon, D. M., Wu, X. Y., Chapman, T., Kailasapathy, K. \& Chin, J. J. (2004). Diversity analysis of commensal porcine Escherichia coli - associations between genotypes and habitat in the porcine gastrointestinal tract. Microbiology 150, 1735-1740.

Ewers, C., Li, G., Wilking, H., Kiessling, S., Alt, K., Antáo, F. M., Laturnus, C., Diehl, I., Glodde, S. \& other authors (2007). Avian pathogenic, uropathogenic, and newborn meningitis-causing Escherichia coli: how closely related are they? Int J Med Microbiol 297, 163-176.

Fairbrother, J. M., Nadeau, E. \& Gyles, C. L. (2005). Escherichia coli in postweaning diarrhea in pigs: an update on bacterial types, pathogenesis, and prevention strategies. Anim Health Res Rev 6, 1739.

Fattal, O. \& Deville, J. G. (2000). Leclercia adecarboxylata peritonitis in a child receiving chronic peritoneal dialysis. Pediatr Nephrol 15, 186187.

Frydendahl, K. (2002). Prevalence of serogroups and virulence genes in Escherichia coli associated with postweaning diarrhoea and edema disease in pigs and a comparison of diagnostic approaches. Vet Microbiol 85, 169-182.

Fujiwara, S., Hashiba, H., Hirota, T. \& Forstner, J. F. (1997). Proteinaceous factor(s) in culture supernatant fluids of bifidobacteria which prevents the binding of enterotoxigenic Escherichia coli to gangliotetraosylceramide. Appl Environ Microbiol 63, 506-512.

Gordon, D. M. \& FitzGibbon, F. (1999). The distribution of enteric bacteria from Australian mammals: host and geographical effects. Microbiology 145, 2663-2671.

Gordon, D. M. \& Lee, J. (1999). The genetic structure of enteric bacteria from Australian mammals. Microbiology 145, 2673-2682.

Hartley, C. L., Neumann, C. S. \& Richmond, M. H. (1979). Adhesion of commensal bacteria to the large intestine wall in humans. Infect Immun 23, 128-132.

Hermansson, I., Einarsson, S., Ekman, L. \& Larsson, K. (1978). On the agalactia post partum in the sow. A hematological and blood chemical study in affected and healthy sows. Nord Vet Med 30, 474481.

Hunter, P. R. \& Gaston, M. A. (1988). Numerical index of the discriminatory ability of typing systems: an application of Simpson's index of diversity. J Clin Microbiol 26, 2465-2466.

Kaper, J. B., Nataro, J. P. \& Mobley, H. L. (2004). Pathogenic Escherichia coli. Nat Rev Microbiol 2, 123-140.

Katouli, M., Lund, A., Wallgren, P., Kuhn, I., Soderlind, O. \& Mollby, R. (1995). Phenotypic characterization of intestinal Escherichia coli of pigs during suckling, postweaning, and fattening periods. Appl Environ Microbiol 61, 778-783.

Katouli, M., Melin, L., Jensen-Waern, M., Wallgren, P. \& Mollby, R. (1999). The effect of zinc oxide supplementation on the stability of the intestinal flora with special reference to composition of coliforms in weaned pigs. J Appl Microbiol 87, 564-573.

Kleta, S., Steinrück, H., Breves, G., Duncker, S., Laturnus, C., Wieler, L. H. \& Schierack, P. (2006). Detection and distribution of probiotic Escherichia coli Nissle 1917 clones in swine herds in Germany. J Appl Microbiol 101, 1357-1366.

Kuhbacher, T., Ott, S. J., Helwig, U., Mimura, T., Rizzello, F., Kleessen, B., Gionchetti, P., Blaut, M., Campieri, M. \& other authors (2006). Bacterial and fungal microbiota in relation to probiotic therapy (VSL\#3) in pouchitis. Gut 55, 833-841.

Kumar, A. \& Sharma, V. K. (1978). Enterobacteria of emerging pathogenic significance from clinical cases in man and animals and detection of toads and wall lizards as their reservoirs. Antonie Van Leeuwenhoek 44, 219-228. 
Lan, P. T., Sakamoto, M. \& Benno, Y. (2004). Effects of two probiotic Lactobacillus strains on jejunal and cecal microbiota of broiler chicken under acute heat stress condition as revealed by molecular analysis of 16S rRNA genes. Microbiol Immunol 48, 917-929.

Lodemann, U., Hubener, K., Jansen, N. \& Martens, H. (2006). Effects of Enterococcus faecium NCIMB 10415 as probiotic supplement on intestinal transport and barrier function of piglets. Arch Anim Nutr 60, 35-48.

Macha, M., Taras, D., Vahjen, W., Arini, A. \& Simon, O. (2004). Specific enumeration of the probiotic strain Enterococcus faecium NCIMB 10415 in the intestinal tract and in faeces of piglets and sows. Arch Anim Nutr 58, 443-452.

Merlino, J., Siarakas, S., Robertson, G. J., Funnell, G. R., Gottlieb, T. \& Bradbury, R. (1996). Evaluation of CHROMagar orientation for differentiation and presumptive identification of Gram-negative bacilli and Enterococcus species. J Clin Microbiol 34, 1788-1793.

Moon, H. W., Hoffman, L. J., Cornick, N. A., Booher, S. L. \& Bosworth, B. T. (1999). Prevalences of some virulence genes among Escherichia coli isolates from swine presented to a diagnostic laboratory in Iowa. $J$ Vet Diagn Invest 11, 557-560.

Moser, I., Lentzsch, P., Rieksneuwoehner, B., Schwerk, P. \& Wieler, L. H. (2002). High resolution genotyping of Campylobacter jejuni strains by macrorestriction analysis with $\mathrm{XhoI}$ and polymerase chain reaction targeting enterobacterial repetitive intergenic consensus sequences: can we predict the zoonotic potential of strains? Epidemiol Infect 129, 435-443.

Nagy, B. \& Fekete, P. Z. (2005). Enterotoxigenic Escherichia coli in veterinary medicine. Int J Med Microbiol 295, 443-454.

National Research Council (1998). Nutrient Requirements of Swine. Washington, DC: National Academic Press.

Omwandho, C. O., Gruessner, S. E. \& Tinneberg, H. R. (2006). Early pregnancy loss and neonatal deaths associated with Klebsiella pneumoniae infection: a mini review of possible occupational health risk. Arch Gynecol Obstet 273, 258-260.

Pollmann, M., Nordhoff, M., Pospischil, A., Tedin, K. \& Wieler, L. H. (2005). Effects of a probiotic strain of Enterococcus faecium on the rate of natural chlamydia infection in swine. Infect Immun 73, 4346-4353.

Ross, R. F., Zimmerman, B. J., Wagner, W. C. \& Cox, D. F. (1975). A field study of coliform mastitis in sows. J Am Vet Med Assoc 167, 231-235.

Scharek, L., Guth, J., Reiter, K., Weyrauch, K. D., Taras, D., Schwerk, P., Schierack, P., Schmidt, M. F., Wieler, L. H. \& Tedin, K. (2005). Influence of a probiotic Enterococcus faecium strain on development of the immune system of sows and piglets. Vet Immunol Immunopathol 105, 151-161.

Scheld, W. M. \& Tyson, G. W. (1979). Citrobacter freundii meningitis in an adult. South Med J 72, 1598-1599.

Schierack, P., Steinruck, H., Kleta, S. \& Vahjen, W. (2006). Virulence factor gene profiles of Escherichia coli isolates from clinically healthy pigs. Appl Environ Microbiol 72, 6680-6686.

Schroeder, B., Duncker, S., Barth, S., Bauerfeind, R., Gruber, A. D., Deppenmeier, S. \& Breves, G. (2006). Preventive effects of the probiotic Escherichia coli strain Nissle 1917 on acute secretory diarrhea in a pig model of intestinal infection. Dig Dis Sci 51, 724731.

Solano-Aguilar, G. I., Vengroski, K. G., Beshah, E. \& Lunney, J. K. (2000). Isolation and purification of lymphocyte subsets from gutassociated lymphoid tissue in neonatal swine. J Immunol Methods 241, 185-199.

Swidsinski, A., Ladhoff, A., Pernthaler, A., Swidsinski, S., LoeningBaucke, V., Ortner, M., Weber, J., Hoffmann, U., Schreiber, S. \& other authors (2002). Mucosal flora in inflammatory bowel disease. Gastroenterology 122, 44-54.

Taras, D., Vahjen, W., Macha, M. \& Simon, O. (2006). Performance, diarrhea incidence, and occurrence of Escherichia coli virulence genes during long-term administration of a probiotic Enterococcus faecium strain to sows and piglets. J Anim Sci 84, 608-617.

Temesgen, Z., Toal, D. R. \& Cockerill, F. R., III (1997). Leclercia adecarboxylata infections: case report and review. Clin Infect Dis 25, 79-81.

Tschape, H., Prager, R., Streckel, W., Fruth, A., Tietze, E. \& Bohme, G. (1995). Verotoxinogenic Citrobacter freundii associated with severe gastroenteritis and cases of haemolytic uraemic syndrome in a nursery school: green butter as the infection source. Epidemiol Infect 114, 441450.

Wieler, L. H., Ilieff, A., Herbst, W., Bauer, C., Vieler, E., Bauerfeind, R., Failing, K., Klös, H., Wengert, D. \& other authors (2001). Prevalence of enteropathogens in suckling and weaned piglets with diarrhoea in southern Germany. J Vet Med B Infect Dis Vet Public Health 48, 151159.

Wunderlich, P. F., Braun, L., Fumagalli, I., D’Apuzzo, V., Heim, F., Karly, M., Lodi, R., Politta, G., Vonbank, F. \& Zeltner, L. (1989). Double-blind report on the efficacy of lactic acid-producing Enterococcus SF68 in the prevention of antibiotic-associated diarrhoea and in the treatment of acute diarrhoea. J Int Med Res 17, 333-338.

Edited by: H. L. Drake 